\title{
NEWCOMERS' SOCIALIZATION: THE PROACTIVE BEHAVIORS, SATISFACTION AND SOCIAL INTEGRATION
}

\author{
F. M. J. J. Kowsikka ${ }^{1}$ \& Robinson James ${ }^{2}$ \\ ${ }^{1}$ franciskowsi@gmail.com, ${ }^{2}$ robinson435@gmail.com \\ Department of Human Resource management \\ University of Jaffna
}

\begin{abstract}
When newcomers enter into organizations they often feel stressed and find difficulties to adjust to the new organizational context. Through the socialization process they learn how to adjust to the new context. Previous studies investigated the role of organizations in the process of newcomer adjustment. However, the individual role in newcomer adjustment has not been sufficiently discussed in the literature; particularly there is no such study in the Sri Lankan context. This study examines the influence of newcomer proactive behaviors (positive framing, relationship building, information seeking and feedback seeking) on adjustment (job satisfaction and social integration). This study was conducted with 114 newcomers who had less than one year of work experience from banking sector in Northern Province of Sri Lanka. The study employed PLS-SEM with Smart PLS to test the proposed hypotheses. The findings revealed that among the four proactive behaviors, positive framing positively influences both satisfaction and social integration. Information seeking, feedback seeking and relationship building also positively influence either job satisfaction or social integration. These findings suggest that newcomers need to engage in proactive behaviors to achieve satisfaction at the workplace and to become acceptable members of the organization. Further, this study contributes to the literature by investigating the influence of proactive behavior in the socialization process among new employees in the banking sector in the Sri Lankan cultural context.
\end{abstract}

Keywords: job satisfaction, social integration, proactive behavior, adjustment, organizational socialization

\section{Introduction}

Organizational socialization is the process through which individuals acquire knowledge about the values, beliefs and behaviors necessary to carry out their work and to adjust to their work context (Van Maanen \& Schein, 1979). New employees 
"entrancein to an organization can be a period of "reality shocks" because of surprises and uncertainty (Reichers, 1987; Louis, 1980). According to Van Maanen (1977) entering into an organization can be deemed a transition that "thrusts one from a state of certainty to uncertainty; from knowing to not knowing; from the familiar to the unfamiliar" (p. 16). During this uncertain situation, in order to achieve successful organizational socialization, the person learns the relevant job skills, acquires a functional level of organizational understanding, attains supportive social interactions with co-workers, and generally accepts the established ways of a particular organization (Taormina, 1997). The employee needs to be proactive and learn how things are done in the new work setting because the organization cannot possibly provide all the information and socialization that the employee needs (Schein, 1968). Unsuccessful newcomer adjustment causes approximately $50 \%$ to $60 \%$ of newcomers to voluntarily or involuntarily leave their new positions within the first 7 months of employment (Leibowitz, Schlossberg, \& Shore, 1991).

Proactive individuals can intentionally and directly change their current social or nonsocial circumstances. Proactive behaviors refer to "anticipatory action that employees take to impact themselves and/or their environments" (Grant \& Ashford, 2008: 8). In order to make differences, proactive individuals act in advance in a self-initiated manner. A number of proactive behaviors related to newcomers' adjustment have been highlighted in the literature. Previous studies investigated the role of organizations in the socialization/adjustment process, but few studies investigated the individual newcomer's role in this process particularly in western cultural context.

There is lack of studies in the Asian cultural context, particularly in Sri Lankan context. Collectivism and high power distance are the two key features of Sri Lankan cultural context. These cultural values influence employees work behavior in organization. Therefore, it is not clear what proactive behaviors do facilitate newcomers to better adjust their job/organizational transition in Sri Lankan context. Therefore, there is a need to investigate the role of newcomers' proactive behaviors on their adjustment in Sri Lankan context.

In relation to newcomers' proactive behavior, a number of proactive behaviors have been identified (Ashford \& Black, 1996; Saks \& Ashforth, 1997). In this study, the researcher considered four widely studied newcomers' proactive behavior: positive framing, information seeking, feedback seeking and relationship building. In previous studies, research scholars have highlighted number of indicators of adjustment of newcomers. Feldman (1981) noted that adjustment consists of three aspects: role 
clarity, self-efficacy and social acceptance. Subsequently, researchers have frequently used role clarity, self-efficacy, and social acceptance as indicators of newcomer adjustment (e.g., Bauer et al., 1998). Further, many studies highlighted that new comers' satisfaction and social integration are indicators of adjustment. In this study, the researcher uses social integration and job satisfaction as indicators of adjustment. Therefore this study aims to investigate the influence of newcomers' positive framing, information seeking, feedback seeking and relationship building on their satisfaction and social integration.

\section{Literature and Hypotheses}

\section{Organizational Socialization}

In Sociology, socialization is the process of internalizing the norms and ideologies of society. Socialization encompasses both learning and teaching and is thus "the means by which social and cultural continuity are attained" (John, 1968). When individuals join organizations; they must learn to understand and make sense of their new surroundings (Louis, 1980). The method by which this sense-making occurs is known as organizational socialization. Organizational socialization is the process by which individuals acquire the attitudes, behaviors, knowledge, and skills required to participate and function effectively as members of an organization (Van Maanen \& Schein, 1979). In the past, many socialization scholars have focused on the role of organization in the socialization process. Recently, there has been an important shift in the socialization literature, with researchers suggesting that newcomers may be proactive agents (Miller \& Jablin, 1991; Reichers, 1987).

\section{Proactive Behavior}

According to organizational research, proactive behavior is a form of motivated work behavior; and refers to as the initiative or anticipatory action that employees take to affect their personal comfort and / or their environments (Bateman \& Crant, 1993; Crant, 2000; Grant \& Ashford, 2008). Because organizations cannot possibly provide all the information and socialization that newcomers need, newcomers must act proactively if they are to reduce uncertainty (Saks \& Ashforth, 1997; Wanberg \& Kammeyer - Muller, 2000). As the socialization literature has explained, newcomer proactivity comprises the self-initiated active steps that new comers take to reduce uncertainty in their work environments (Ashford \& Black, 1996; Saks \& Ashforth, 1997). 


\section{Positive Framing}

Positive framing is a cognitive self-management mechanism that employees use "to alter their understanding of a situation by explicitly controlling the cognitive frame they place on the situation" (Ashford \& Black, 1996). People who engage in positive framing look on the positive side of things and view situations as an opportunity rather than a threat. Put differently, positive framing involves interpreting events in the environment as supportive rather than antagonistic.

Positive framing can be regarded as a behavior of cognitive self-management. Folkman (1984) labeled positive framing as primary appraisal and argued that in stress situations, such appraisals influence subsequent coping responses. Taylor and Brown (1988) labeled these cognitive frames as positive illusions and noted their beneficial effects on individuals' stress levels, recovery from illness, depression, and capability of creative and productive work.

Newcomers attempt to frame their new situations positively to alter how they understand the situation to gain cognitive control. The actual situation and their actual level of control within the situation remain unchanged. However, the logic of this tactic as a control mechanism gives people a sense of control by increasing their selfconfidence and sense of efficacy with respect to the situation. It is suggested that positive framing is significantly related to social integration, role clarity, personorganization fit, job satisfaction, job performance and turnover intension (Ashford \& Black, 1996; Gruman et al., 2006; Kim et al., 2005; Wanberg \& Kammeyer - Mueller, 2000). Researchers found that positive framing is related to newcomer performance and job satisfaction (Ashford \& Black, 1996). Therefore, it can be proposed that positive framing influence newcomers' adjustment.

\section{Information Seeking}

It is the employee's search for and acquisition of information that is related to the job, organization and social context. New employees can acquire information from other newcomers, co-workers, supervisors, mentors and written materials. In that way, they learn the formal and informal rules and regulations of the organization.

To date, there has been little empirical work in this area, and what does exist has been largely exploratory (Comer, 1991; Miller, 1991). Morrison (1993) categorizes the types of information that newcomers seek. He suggested that, with the existing research on socialization, newcomers have to learn about what to do and how to do, 
meaning they must learn specific job related skills and knowledge to perform their new job well. Thus he proposed that one type of information newcomers proactively seek is technical information, or information about how to perform required job task and newcomers information seeking is related to satisfaction, performance and intentions to leave (Morrison, 1993).

In addition to newcomers mastering their job, the research on socialization suggests that they need to define their job roles in organizations. So the second type of information Morrison (1993) emphasized is referent information. It is related to the role demands and expectations. Besides, newcomers need to be integrated in to the work group by learning its culture which is described as normative information. By identifying prevailing values and norms of the organization, the new employee can learn expected behaviors and attitudes within the new working environment. As employees gain information about their tasks, duties and social expectations in their work setting, they are able to reduce uncertainty and make sense of their new environment (Miller \& Jablin, 1991; Saks \& Ashford, 1997a). Information seeking is important for organizational newcomers because it reduces uncertainty and increase control (Berger, 1979; Berlyne, 1960; Lanzetta, 1971)

\section{Feedback Seeking}

Feedback seeking is the process of an employee's solicitation of information about his or her performance (Ashford \& Black, 1996). Feedback is especially important for newcomers (Wanberg \& Kammeyer - Mueller, 2000), because they are more likely to misinterpret the environment, make mistakes, and violate organizational norms than individuals who have completed the socialization process (Ashford \& Taylor, 1990). According to Ash ford and Taylor (1990), feedback also allows new employees to understand when they need to learn more or when they need to reinterpret past information.

When an individual enters in to a new organization and starts a new job, he or she may be anxious because of uncertainty about the new environment. Although organization will provide some necessary information, to the newcomers, it is far from enough. Therefore, newcomers need to proactively seek information about the job content, role and co-workers to reduce uncertainty and anxiety. Information seeking serves to reduce uncertainty and equip the employee with knowledge about performance expectations, norms and relationships, so as to make the work environment more predictable (Saks \&Ash forth, 1997a). 


\section{Relationship Building}

Relationship building is the behaviors of the new employee directed towards initiating social interaction in the work environment (Ashford \& Black, 1996). Relationship building is important for organizational newcomers as a means of avoiding loneliness and social isolation (Nelson \& Quick, 1991). It denotes the relationship that newcomers form with co-workers, supervisors and mentors. It is helpful to newcomers to acquire knowledge, get support and reduce stress. Previous research has indicated that relationship building tactics are important to the socialization process (e.g., Ashford \& Black, 1996).

According to Chao et al. (1994), people are also important for providing information, resources and support, thereby increasing control perceptions and predictability in the work environment. Ashford and Black (1996) categorized proactive behaviors geared towards relationship building to networking, general socializing and building relationships with one's boss. These proactive behaviors build friendship networks (Nelson \& Quick, 1991) and help to learn appropriate skills, role expectations as well as organizational policies (Ashford \& Black, 1996; Morrison, 1993, 2002; Reichers, 1987). Relationship building has been related to social integration, role clarity, person organization fit, job satisfaction, job performance and turnover (Gruman et al., 2006; Wanberg \& Kammeyer - Mueller, 2000; Ashford \& Black, 1996). Ashford \& Black (1996) suggests relationship building is one of the determining factors of newcomers' socialization.

\section{Job Satisfaction}

Spector (1997) defines to job satisfaction in terms of how people feel about their jobs. Ellickson and Logsdon (2002) support this view by defining job satisfaction as the extent to which employees like their work. Schermerhorn (1993) defines job satisfaction as an affective or emotional response towards various aspects of an employee's work. Job satisfaction and dissatisfaction are not only dependent on the nature of the job, but also on the expectations of what the job supplies to an employee (Hussami, 2008). Higher organizational, social and intrinsic reward will increase job satisfaction (Mulinge and Mullier, 1998; Willem et al., 2007).

The positive psychological and emotional condition emanating from the valuation of one's job and related job experiences influence the level of an employee's job satisfaction (Locke, 1976). When features of individuals' job go beyond their 
expectations they feel more satisfied. Calvo - Salguero et al. (2010) also, defined job satisfaction as an attitude relating to the extent to which employees like or dislike their job and job satisfaction is one of the adjustment indicator of newcomers. Individual engagement in proactive behaviors such as information seeking, positive framing, feedback seeking and relationship building reduce newcomers' uncertainty and thus make them satisfied with their work.

\section{Social Integration}

Social integration refers to the extent to which newcomers experience cooperative social interaction with their group members, satisfaction with other group members, and attraction to the group (Wang \& Kim, 2013:392). Social integration which is also described as newcomers' developing a social sense of the organizational environment and to be liked and accepted by peers is considered one of the most critical indicators of newcomers' adjustment (Bauer \& Gren, 1998; Morrison, 1993;). As a result of access to people and network, social integration gives a sense of control, makes the organizational environment predictable, and thereby allows newcomers have socialcapital resources whenever they need information and support (Ashford \& Black, 1996).

By actively seeking information and feedback and knowing what others expect them to do, newcomers understand more clearly the difference between being or not being a member of the organization and thereby increase their perceived insider status (Masterson \& Stamper, 2003). Furthermore building relationships enable newcomers to interact frequently with their coworkers and help them acquire interpersonal skills needed for cooperation (Wanberg \& Kammeyer - Mueller, 2000). The close interaction with group members enables newcomers to form a positive impression about an organization's environment towards its new employees (Wang \& Kim, 2013). Previous studies highlighted integration into a social group to involve the establishment of a situational identity and that those who successfully establish an identity through social interactions to be more strongly identified with the organization as a whole. Based on the objectives and literature review, the present study propose the following eight hypotheses

H1a: Positive framing positively influence social integration

$\mathrm{H} 1 \mathrm{~b}$ : Positive framing positively influence satisfaction

H2a: Information seeking positively influence social integration 
$\mathrm{H} 2 \mathrm{~b}$ : Information seeking positively influence satisfaction

H3a: Feedback seeking positively influence social integration

$\mathrm{H} 3 \mathrm{~b}$ : Feedback seeking positively influence satisfaction

$\mathrm{H} 4 \mathrm{a}$ : Relationship building positively influence social integration

H4b: Relationship building positively influence satisfaction

\section{Method}

This is a cross-sectional study. This study was conducted with 114 newcomers who had less than one year of work experience in the banking sector in the Northern Province of Sri Lanka. Out of the 250 questionnaires distributed randomly to the employees who have been recruited recently (within one year) in the banking sector, 124 questionnaires were received (response rate of $50 \%$ ). Of those returned, only 114 questionnaires were in a usable state (effective response rate of $46 \%$ ). The researchers employed convenience sampling technique and the data collection was done through a self-administered anonymous questionnaire. A pilot test was conducted using 10 employees in order to identify issues associated with the measures, questionnaire design, etc. Then the data were tested to ensure normality, linearity, homoscedasticity, validity, reliability, correlation, absence of multicollinearity and common method bias.

\section{Data analysis Procedures}

First, the survey data were entered into a Microsoft Excel sheet and then transferred to SPSS 20 for data cleaning and analysis. PLS-SEM was employed with Smart PLS version 3.2.7 to analyze both the measurement and structural model. The researcher took the necessary steps to minimize CMV issues in the survey at both the design stage and the analysis stage as suggested by Chang Podsak off et al. (2003).

\section{Measures}

Positive Framing - In this study, positive framing is stated as a cognitive selfmanagement mechanism that employees use "to alter their understanding of a situation by explicitly controlling the cognitive frame they place on the situation" (Ashford \& Black, 1996). To measure positive framing, this research uses questionnaire developed by Ashford and Black (1996). The indicators are measured on a 5-point Likert - scale, with " 1 " denoting strongly disagree and "5" strongly agree. Example items are; "I tried to see my situation as an opportunity rather than a threat", 
"I tried to look on the bright side of things". Reliability (Cronbach's Alpha) of this measure of the current study was greater than the threshold value of 0.7 .

Relationship Building - This study notes that relation ship building relates to the behaviors on the part of the new employee that are directed towards initiating social interaction in the work environment (Ashford \& Black, 1996). To measure relationship building, this research uses questionnaire conducted by Ashford and Black (1996). This scale is based on a 5-point Likert - scale, with "1" indicating strongly disagree and " 5 " strongly agree. Example items are; "I tried to spend as much time as I could with my boss", "I started conversations with people from different segments of the company". Previous studies and the current study demonstrate acceptable Cronbach's Alpha value.

Information seeking- Information seeking denotes the employee's search for and acquisition of information that is related to the job, organization and social context (Miller \& Jablin, 1991). To measure information seeking, this research uses scale developed by Ashford and Black (1996). This scale is based on a 5-point Likert - scale, with " 1 " signifying strongly disagree and " 5 " strongly agree. Example items are; "I tried to learn the (official) organizational structure", "I tried to learn the important policies and procedures in the organization".Cronbach's Alpha value of this measure in the current study was greater than the threshold value of 0.7 .

Feedback Seeking-Feedback seeking suggests an employee soliciting information about his or her performance (Ashford \& Black, 1996). To measure feedback seeking, this research uses questionnaire conducted by Ashford and Black (1996). The scale is based on a 5-point Likert - scale, with "1" designating strongly disagree and "5" strongly agree. Example items are; "I sought out feedback on my performance after assignments", "I asked my boss's opinion of my work". Cronbach's Alpha value of this measure of the current study was greater than the threshold value of 0.7 .

Job Satisfaction - In this study job satisfaction is stated as an affective or emotional response towards various aspects of an employee's work (Schermerhorn, 1993). To measure job satisfaction, this research uses questionnaire developed by Cammann (1983).The indicators are measured on a 5-point Likert - scale, with " 1 " implying strongly disagree and " 5 " strongly agree. Example items are; "All in all, I am satisfied with my job", "In general, I like working here". Cronbach's Alpha value of this measure in the current study was greater than the threshold value of 0.7 . 
Social Integration-Social integration refers to the extent to which newcomers experience cooperative social interaction with their group members, satisfaction with other group members, and attraction to the group (Wang \& Kim, 2013). In this study social integration was measured with a scale developed by Morrison (1993a). The indicators are measured on a 5-point Likert - scale, with "1" suggesting strongly disagree and "5" strongly agree. Example items are; "I feel comfortable around my coworkers", "My co-workers seem to accept me as one of them." Cronbach's Alpha value of this measure in the current study was greater than the threshold value of 0.7 .

\section{Reliability and Validity}

Reliability and validity of the constructs were assessed through widely accepted criteria. Cronbach's alpha, and composite reliability of each construct were larger than the threshold value of 0.70 and AVE of each construct was above the threshold value of 0.50 (Table 1). Factor loading of each indicator were greater than the accepted value of 0.7 (Table 2).

\section{Table 1: Construct reliability and validity}

\begin{tabular}{|l|l|l|l|}
\hline Constructs & Cronbach's Alpha & Composite Reliability & (AVE) \\
\hline Feedback seeking (FBS) & 0.80 & 0.88 & 0.71 \\
\hline Information seeking (INS) & 0.83 & 0.90 & 0.74 \\
\hline Relationship building (REB) & 0.88 & 0.92 & 0.73 \\
\hline Satisfaction (SAT) & 0.89 & 0.93 & 0.82 \\
\hline Social integration (SOI) & 0.93 & 0.95 & 0.83 \\
\hline Positive framing (PFR) & 0.89 & 0.93 & 0.82 \\
\hline
\end{tabular}

Note: $A V E=$ average variance extracted

Table 2: Outer Loading

\begin{tabular}{|l|r|r|l|l|l|l|}
\hline & \multicolumn{1}{|l|}{ FBS } & \multicolumn{1}{l|}{ INS } & REB & SAT & SOI & PFR \\
\hline FBS_1 & 0.90 & & & & & \\
\hline FBS_2 & 0.91 & & & & & \\
\hline FBS_3 & 0.70 & & & & & \\
\hline INS_1 & & 0.91 & & & & \\
\hline INS_2 & & 0.82 & & & & \\
\hline INS_4 & & 0.86 & & & & \\
\hline PFR_1 & & & & & & 0.86 \\
\hline PFR_2 & & & & & & 0.93 \\
\hline
\end{tabular}




\begin{tabular}{|l|l|l|r|r|r|r|}
\hline PFR_3 & & & & & & 0.93 \\
\hline REB_1 & & & 0.81 & & & \\
\hline REB_2 & & & 0.85 & & & \\
\hline REB_3 & & & 0.86 & & & \\
\hline REB_4 & & & 0.89 & & & \\
\hline SAT-1 & & & & 0.88 & & \\
\hline SAT_2 & & & & 0.95 & & \\
\hline SAT_3 & & & & 0.89 & & \\
\hline SOI-2 & & & & & 0.94 & \\
\hline SOI-3 & & & & & 0.89 & \\
\hline SOI-4 & & & & & 0.89 & \\
\hline SOI_1 & & & & & 0.93 & \\
\hline
\end{tabular}

To assess discriminant validity of the constructs two criteria were used: a) square root of AVE of each construct is larger than the largest correlation of other constructs (Fornell - Larcker criterion), b) an indicator's loading with its related construct should be higher than its cross loading. The results show that square root of AVE of each construct is larger than the largest correlation of other constructs (see table 3 ) and each indicator's loadings to the specified constructs is significantly higher than the loading of any other constructs (see table 4). Therefore it can be said that the measurement model demonstrating adequate discriminant validity (Hair et al., 2011).

Table 3: Fornell-Larcker criterion analysis for checking discriminant validity

\begin{tabular}{|l|l|l|l|l|l|l|}
\hline & FBS & INS & REB & SAT & SOI & PFR \\
\hline FBS & $\mathbf{0 . 8 4}$ & & & & & \\
\hline INS & 0.29 & $\mathbf{0 . 8 6}$ & & & & \\
\hline REB & 0.44 & 0.33 & $\mathbf{0 . 8 6}$ & & & \\
\hline SAT & 0.31 & 0.13 & 0.51 & $\mathbf{0 . 9 1}$ & & \\
\hline SOI & 0.50 & 0.37 & 0.40 & 0.56 & $\mathbf{0 . 9 1}$ & \\
\hline PFR & 0.26 & 0.24 & 0.42 & 0.56 & 0.51 & $\mathbf{0 . 9 1}$ \\
\hline
\end{tabular}

Note: bold diagonal figures (bold) are the square root of $A V E$.

Table4: Loading and cross loading

\begin{tabular}{|l|c|r|r|r|r|r|}
\hline & \multicolumn{1}{|l|}{ FBS } & \multicolumn{1}{|c|}{ INS } & \multicolumn{1}{c|}{ REB } & \multicolumn{1}{c|}{ SAT } & \multicolumn{1}{c|}{ SOI } & \multicolumn{1}{l|}{ PFR } \\
\hline FBS_1 & $\mathbf{0 . 9 0}$ & 0.31 & 0.45 & 0.23 & 0.43 & 0.19 \\
\hline FBS_2 & $\mathbf{0 . 9 1}$ & 0.31 & 0.39 & 0.35 & 0.51 & 0.34 \\
\hline FBS_3 & $\mathbf{0 . 7 0}$ & 0.00 & 0.23 & 0.16 & 0.25 & 0.03 \\
\hline
\end{tabular}




\begin{tabular}{|l|r|r|r|r|r|r|}
\hline INS_1 & 0.25 & $\mathbf{0 . 9 1}$ & 0.27 & 0.14 & 0.34 & 0.20 \\
\hline INS_2 & 0.20 & $\mathbf{0 . 8 2}$ & 0.38 & 0.13 & 0.27 & 0.22 \\
\hline INS_4 & 0.30 & $\mathbf{0 . 8 6}$ & 0.22 & 0.06 & 0.34 & 0.21 \\
\hline PFR_1 & 0.25 & 0.32 & 0.41 & 0.42 & 0.41 & $\mathbf{0 . 8 6}$ \\
\hline PFR_2 & 0.23 & 0.15 & 0.35 & 0.52 & 0.50 & $\mathbf{0 . 9 3}$ \\
\hline PFR_3 & 0.23 & 0.21 & 0.38 & 0.56 & 0.46 & $\mathbf{0 . 9 3}$ \\
\hline REB_1 & 0.39 & 0.29 & $\mathbf{0 . 8 1}$ & 0.36 & 0.34 & 0.33 \\
\hline REB_2 & 0.36 & 0.23 & $\mathbf{0 . 8 5}$ & 0.40 & 0.25 & 0.39 \\
\hline REB_3 & 0.32 & 0.24 & $\mathbf{0 . 8 6}$ & 0.48 & 0.32 & 0.35 \\
\hline REB_4 & 0.43 & 0.35 & $\mathbf{0 . 8 9}$ & 0.50 & 0.43 & 0.36 \\
\hline SAT-1 & 0.34 & 0.10 & 0.42 & $\mathbf{0 . 8 8}$ & 0.54 & 0.46 \\
\hline SAT_2 & 0.30 & 0.17 & 0.51 & $\mathbf{0 . 9 5}$ & 0.54 & 0.55 \\
\hline SAT_3 & 0.21 & 0.07 & 0.46 & $\mathbf{0 . 8 9}$ & 0.43 & 0.50 \\
\hline SOI-2 & 0.52 & 0.34 & 0.41 & 0.50 & $\mathbf{0 . 9 4}$ & 0.42 \\
\hline SOI-3 & 0.45 & 0.41 & 0.35 & 0.51 & $\mathbf{0 . 8 9}$ & 0.52 \\
\hline SOI-4 & 0.43 & 0.28 & 0.34 & 0.49 & $\mathbf{0 . 8 9}$ & 0.40 \\
\hline SOI_1 & 0.41 & 0.30 & 0.36 & 0.53 & $\mathbf{0 . 9 3}$ & 0.49 \\
\hline
\end{tabular}

Following the measurement model quality assessment, the structural model quality was assessed through widely accepted criteria: Multicoliniarity, significance of path coefficient, variance explained, predictive relevance (Q2) and the effect size (f2). The results showed that the said structural model criteria were at acceptable level and thus the existence of structural model quality was ensured.

After confirming the quality of the structural model and the measurement model, the researcher run the model to test the proposed hypothesis. The path coefficient of each proposed path are shown in figure 1. As shown in figure 1, all relationships are in the expected direction except the relationship between information seeking and satisfaction. 


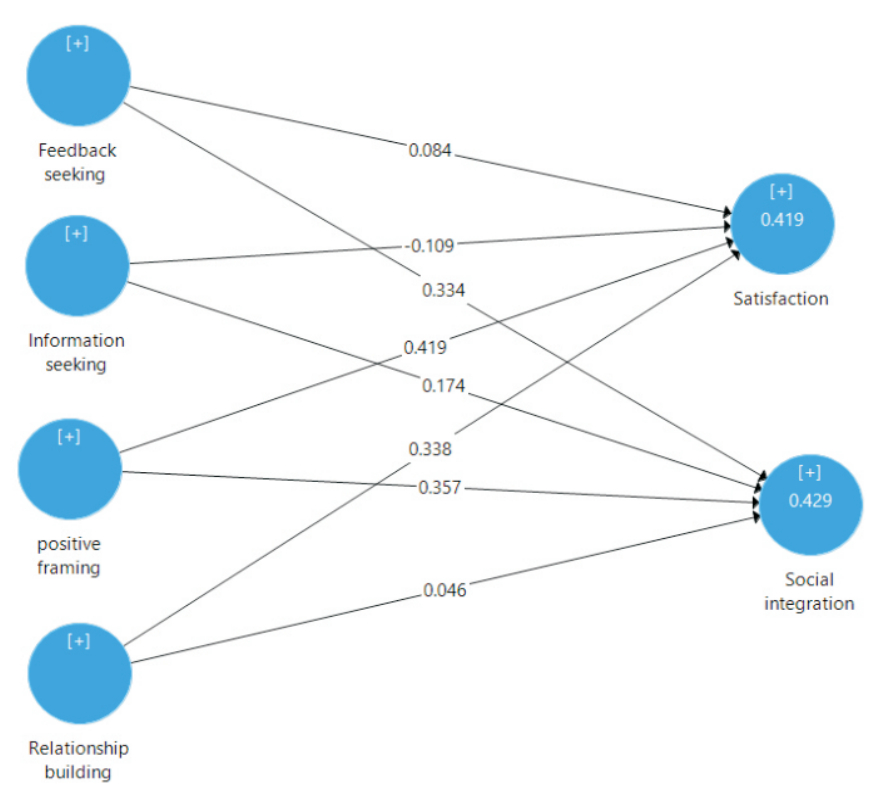

Significance of path's coefficients were assessed through bootstrapping with 5000 sub-samples and the results were tabulated in table 4 below. The results indicate that out of eight proposed relationships only five relationships were positive and significant as expected.

Table 4. Path Coefficient and its Significance

\begin{tabular}{|l|l|l|l|}
\hline Path Relationship & Path coefficient & T Statistics & P Values \\
\hline Feedback seeking-> Satisfaction & 0.08 & 0.85 & 0.40 \\
\hline Feedback seeking-> Social integration & $\mathbf{0 . 3 3}$ & $\mathbf{4 . 2 0}$ & $\mathbf{0 . 0 0}$ \\
\hline Information seeking-> Satisfaction & -0.11 & 1.92 & 0.06 \\
\hline Information seeking> Social integration & $\mathbf{0 . 1 7}$ & $\mathbf{3 . 0 0}$ & $\mathbf{0 . 0 0}$ \\
\hline Relationship building > Satisfaction & $\mathbf{0 . 3 4}$ & $\mathbf{3 . 9 5}$ & $\mathbf{0 . 0 0}$ \\
\hline Relationship building> Social integration & 0.05 & 0.58 & 0.56 \\
\hline Positive framing-> Satisfaction & $\mathbf{0 . 4 2}$ & $\mathbf{4 . 7 2}$ & $\mathbf{0 . 0 0}$ \\
\hline Positive framing-> Social integration & $\mathbf{0 . 3 6}$ & $\mathbf{4 . 5 9}$ & $\mathbf{0 . 0 0}$ \\
\hline
\end{tabular}

The results indicate that feedback seeking, information seeking and positive framing have significant influence on social integration. But unexpectedly relationship building has no significant influence on social integration. As expected, relationship building and positive framing have significant influence on satisfaction. But, unexpectedly, feedback seeking and information seeking have no significant 
influence on satisfaction. Further, all these four predictor variables together explain $42 \%$ and $43 \%$ of variance in satisfaction and social integration respectively.

\section{Discussion and Conclusion}

When newcomers enter into an organization, they feel stressed and encounter difficulties to adjust to the new organizational context. Previous studies investigated the role of organizations in the socialization process, but the individual's role in the socialization process is under researched. This study investigated the individual's role in the socialization process in the form of proactive behaviors and found individuals' engagement in proactive behavior leads to positive socialization outcomes such as social integration and satisfaction.

This study found newcomers' engagement in proactive behaviors such as feedback seeking, information seeking, and positive framing positively influence their social integration while positive framing and relationship building positively influence their satisfaction. It can be noted that proactive engagement in positive framing significantly influence both satisfaction and social integration with more effect on both social integration and satisfaction than other proactive behaviors. Other three (relationship building, feedback seeking and information seeking) proactive behaviors significantly influence either newcomers' satisfaction or social integration.

Positive framing is likely to have a positive impact on newcomer job satisfaction and social integration. The positive framing is associated with positive emotions and mood (Sohl \& Moyer, 2009) that enhance general feelings of job satisfaction and newcomers socially integrated (Brockner \& Higgins, 2001). Newcomers who engage in positive framing are confident and mentally strong at the work place that may lead to satisfaction. Seeing the positive side of the situation enables newcomers to mix with others in the organization without prejudice and to become acceptable members of the organization. The positive influence of positive framing on adjustment indicators has been highlighted in the literature (Brief, Butcher, \& Roberson, 1995; Lanaj, Chang, \& Johnson, 2012) and the results of this study are consistent with previous studies.

The findings of this study suggest that building relationship with the boss and organizational members is positively related with newcomer's satisfaction. This finding is consistent with the findings of Gruman et al. (2006). Newcomers who explicitly attempted to build relationships with their bosses reported receiving higher performance ratings from their bosses than those who did not. Newcomers who 
engage in relationship building with others and initiating conversations may reduce uncertainty and increase their satisfaction. Relationship building is related to job satisfaction because relationship building may be a means of avoiding loneliness and social isolation.

Previous studies highlighted that relationship building is associated with social integration, role clarity, person organization fit, job satisfaction, job performance and turnover intention (Ashford \& Black, 1996; Gruman et al., 2006; Kim et al., 2005; Wanberg \& Kammeyer - Mueller, 2000). Unexpectedly, in this study, the relationship building was not a predictor of social integration. One possible reason for the unexpected finding is the nature of the work. Respondents were working under competitive or stiff environment and the employees who stand out to build relationship with supervisors in the organizations were more likely to be disliked and regarded as shoe polishers (Xaio Li, 2016).

This study proposed that feedback seeking and information seeking are the predictors of satisfaction and social integration. As expected feedback seeking and information seeking were positively related to social integration. But unexpectedly, both feedback seeking and information seeking are not significant predictors of satisfaction. But, the findings may be attributed to the way of the information is sought. Applying observation as a way of acquiring information is not risky but by directly asking for information may not be welcomed by the organizational members. Also seeking information with inappropriate conversation may give some adverse effects. Newcomers experience frustration, anxiety, and stress and individual driven initiatives can help reduce worse experiences at a minimal cost. Organizations must support newcomers' initiatives in the process of socialization and adjustment.

Newcomers' engagement in proactive behaviors leads to positive individual and organizational level outcomes (Ashford \& Black, 1996; Gruman and Saks, 2012). Newcomers need to be proactive and engage in information seeking, relationship building, feedback seeking and positive framing to achieve satisfaction, become acceptable members of the organization and to be successful in their careers. Also, organizations need to encourage newcomers to engage in proactive behavior through maintaining appropriate organizational culture to get better outcomes from their employees. Further, this study contributes to the literature on the role of proactive behavior in satisfaction and social integration by investigating the influence of proactive behavior in the socialization process among bank employees in the Northern Province of Sri Lanka, a population that has not been researched in the literature. 


\section{Limitations and Suggestion for Further Research}

This study was conducted among only bank employees in the Northern Province of Sri Lanka and thus generalization of this study is limited. This study entirely depended on cross-sectional and self-reported data and used small number of respondents. Further studies can adopt longitudinal approach to avoid common method bias issues. Investigating additional antecedents and outcomes of proactive socialization behaviors would provide meaningful insights into the proactive socialization research. There are a number of proactive behaviors that have been highlighted in the literature but this study focused only on four proactive behaviors and explained only $42 \%$ and $43 \%$ variance in satisfaction and adjustment respectively. Also this study considered only two adjustment indicators: social integration and satisfaction though several indicators of adjustment that are highlighted in the literature. Future studies can investigate the influence of other proactive behaviors on adjustment and adjustment can be measured with other indicators such as person-organization fit and performance.

\section{References}

Ashford, S. J., \& Black, J. S. (1996). Proactivity during organizational entry: The role of desire for control. Journal of Applied psychology, 81(2), 199-214

Bateman, T. S., \&Crant, J. M. (1993). The proactive component of organizational behavior: A measure and correlates. Journal of organizational behavior, 14(2), 103-118

Bauer, T. N., \& Green, S. G. (1998).Testing the combined effects of newcomer information seeking and manager behavior on socialization. Journal of Applied Psychology, 83(1), 72.

Bauer, T. N., \& Green, S. G. (1998).Testing the combined effects of newcomer information seeking and manager behavior on socialization. Journal of Applied Psychology, 83(1), 72.

Berger, C. R. (1979). Beyond initial interaction: Uncertainty, understanding, and the development of interpersonal relationships. Language and social psychology, 122-144

Brief, A. P., Butcher, A. H., \& Roberson, L. (1995). Cookies, disposition, and job attitudes: The effects of positive mood-inducing events and negative affectivity on job satisfaction in a field experiment. Organizational Behavior and Human Decision Processes, 62(1), 55-62 
Brockner, J., \& Higgins, E. T. (2001). Regulatory focus theory: Implications for the study of emotions at work. Organizational behavior and human decision processes, 86(1), 35-66

Berlyne, D. E. (1960) Conflict, arousal, and curiosity. McGraw-Hill series in psychology. New York, McGraw-Hill Book Company.

Cammann, C. (1983). Assessing the attitudes and perceptions of organizational members. Assessing organizational change: A guide to methods, measures, and practices, 71-138.Chao, G. T., O'Leary-Kelly, A. M., Wolf, S., Klein, H. J., \&Gardner, P. D. (1994). Organizational socialization: Its content and consequences. Journal of Applied psychology, 79(5), 730.

Clausen, J. A. (1968). Recent developments in socialization theory and research. The ANNALS of the American Academy of Political and Social Science, 377(1), 139-155.Comer, D.R.(1991).Organizational newcomers' acquisition of information from peers. Management communication quarterly, 5(1), 64-89.

Crant, J. M. (2000). Proactive behavior in organizations. Journal of management, 26(3), 435-462.

Ellickson, M. C., \& Logsdon, K. (2002).Determinants of job satisfaction of municipal government employees. Public Personnel Management, 31(3), 343-358

Feldman, D. C. (1981). The multiple socialization of organization members. Academy of management review, 6(2), 309-318

Folkman, S. (1984). Personal control and stress and coping processes: a theoretical analysis. Journal of personality and social psychology, 46(4), 839.

Grant, A. M., \& Ashford, S. J. (2008). The dynamics of proactivity at work. Research in organizational behavior, 28, 3-34.

Gruman, J. A., Saks, A. M., \& Zweig, D. I. (2006). Organizational socialization tactics and newcomer proactive behaviors: An integrative study. Journal of vocational behavior, 69(1), 90-104.

Hair, J. F., Sarstedt, M., Pieper, T. M., \&Ringle, C. M. (2012). The use of partial least squares structural equation modeling in strategic management research: a review of past practices and recommendations for future applications. Long range planning, 45(5-6), 320-340.

Kim, T. Y., Cable, D. M., \& Kim, S. P. (2005). Socialization tactics, employee proactivity, and person-organization fit. Journal of Applied Psychology, 90(2), 232.

Lanaj, K., Chang, C. H., \& Johnson, R. E. (2012). Regulatory focus and work-related outcomes: a review and meta-analysis. Psychological bulletin, 138(5), 998. 
Lanzetta, J. T. (1971). The motivational properties of uncertainty. Intrinsic motivation: A new direction in education, 134-147.

Lazarus, R. S., \& Folkman, S. (1984). Stress, appraisal, and coping. Springer publishing company.

Leibowitz, Z. B., Schlossberg, N. K., \& Shore, J. E. (1991).Stopping the revolving door. Training \& Development, 45(2), 43-51.

Locke, E. A. (1976). The nature and causes of job satisfaction. Handbook of industrial and organizational psychology.

Louis, M. R. (1980). Surprise and sense making: What newcomers experience in entering unfamiliar organizational settings. Administrative science quarterly, 226-251.

Mahmoud, A. H. (2008). A study of nurses' job satisfaction: the relationship to organizational commitment, perceived organizational support, transactional leadership, transformational leadership, and level of education. European journal of scientific research, 22(2), 286-295.

Masterson, S. S., \& Stamper, C. L. (2003). Perceived organizational membership: An aggregate framework representing the employee-organization relationship. Journal of Organizational Behavior: The International Journal of Industrial, Occupational and Organizational Psychology and Behavior, 24(5), 473-490.

Miller, V. D., \&Jablin, F. M. (1991). Information seeking during organizational entry: Influences, tactics, and a model of the process. Academy of Management Review, 16(1), 92-120.

Morrison, E. W. (1993). Longitudinal study of the effects of information seeking on newcomer socialization. Journal of applied psychology, 78(2), 173.

Mulinge, M., \& Mueller, C. W. (1998). Employee job satisfaction in developing countries: the case of Kenya. World Development, 26(12), 2181-2199.

Nelson, D. L., \& Quick, J. C. (1991). Social support and newcomer adjustment in organizations: attachment theory at work? Journal of organizational behavior, 12(6), 543-554.

Parker, S. K., \& Collins, C. G. (2010).Taking stock: Integrating and differentiating multiple proactive behaviors. Journal of Management, 36(3), 633-662.

Podsakoff, P. M., MacKenzie, S. B., Lee, J. Y., \&Podsakoff, N. P. (2003). Common method biases in behavioral research: A critical review of the literature and recommended remedies. Journal of applied psychology, 88(5), 879.

Reichers, A. E. (1987). An interactionist perspective on newcomer socialization rates. Academy of management review, 12(2), 278-287. 
Saks, A. M., \&Gruman, J. A. (2012).Getting newcomers on board: A review of socialization practices and introduction to socialization resources theory. The Oxford handbook of organizational socialization, 27-55.

Saks, A. M., \&Ashforth, B. E. (1997). Organizational socialization: Making sense of the past and present as a prologue for the future. Journal of vocational Behavior, 51(2), 234-279.

Schein, E. H. (1968). The individual, the organization, and the career: A conceptual scheme.

Sohl, S. J., \& Moyer, A. (2009).Refining the conceptualization of a future-oriented self-regulatory behavior: Proactive coping. Personality and Individual Differences, 47(2), 139-144.

Spector, P. E. (1997). Job satisfaction: Application, assessment, causes, and consequences (Vol. 3). Sage publications.

Taormina, R. J. (1997). Organizational socialization: A multidomain, continuous process model. International Journal of Selection and Assessment, 5(1), 29-47.

Taylor, S. E., \& Brown, J. D. (1988). Illusion and well-being: a social psychological perspective on mental health. Psychological bulletin, 103(2), 193.

Van Maanen, J. E., \& Schein, E. H. (1977).Toward a theory of organizational socialization.

Van Maanen, J., Schein, E. H., \&Staw, B. M. (1979).Research in organizational behavior. BM Staw (Ed.), 209-264

Wanberg, C. R., \&Kammeyer-Mueller, J. D. (2000).Predictors and outcomes of proactivity in the socialization process. Journal of applied psychology, 85(3), 373.

Wang, J., \& Kim, T. Y. (2013). Proactive socialization behavior in China: The mediating role of perceived insider status and the moderating role of supervisors' traditionality. Journal of Organizational Behavior, 34(3), 389-406.

Willem, A., Buelens, M., \& De Jonghe, I. (2007). Impact of organizational structure on nurses' job satisfaction: A questionnaire survey. International journal of nursing studies, 44(6), 1011-1020. 